\title{
Construction dewatering in reclaimed land in Hong Kong - a review of best practices
}

\author{
Rich Laver \\ Golder Associates Ltd, Hong Kong, People's Republic of China
}

\begin{abstract}
A sound understanding of groundwater engineering principles is a prerequisite for effective construction dewatering and the associated pumping tests. This paper makes practical recommendations to improve dewatering designs in reclaimed land in Hong Kong and the interpretation of groundwater monitoring data. The paper first introduces the reader to the hydrogeology of Hong Kong and its implications on dewatering. It then draws upon experiences in Hong Kong, reviewing and recommending best practices in groundwater monitoring, and the design of extraction and recharge wells.
\end{abstract}

KEYWORDS Dewatering; pumping test; groundwater; instrumentation; monitoring

CONTACT Rich Laver rich.laver@gmail.com

Received 18 July 2020

\section{Introduction}

Excavations below the groundwater table require dewatering for construction to progress in dry conditions. Before dewatering and excavation can commence, the Government's approval process in Hong Kong typically requires the successful completion of a pumping test. The purpose of the pumping test is to demonstrate the provision of adequate dewatering capacity and ensure an acceptable impact upon sensitive receivers.

Construction dewatering is widely employed in Hong Kong, yet sometimes dewatering design appears to be guided by local practice rather than by groundwater engineering principles. This occasionally results in ineffective dewatering and the misinterpretation of pumping tests.

This paper reviews the construction dewatering practices in Hong Kong. Drawing upon project experiences and the principles of groundwater engineering, practical recommendations are made to improve the effectiveness of dewatering designs and the interpretation of groundwater monitoring data. The theory behind the recommendations is presented to equip the readers with a fundamental understanding of groundwater engineering principles. Readers are first introduced to the hydrogeology of Hong Kong and its implications on dewatering. The following sections then review and recommend best practices in groundwater monitoring, and the design of extraction and recharge wells.

\section{Offshore stratigraphy of Hong Kong}

Major construction projects requiring dewatering are typically situated in low-lying areas which have previously been reclaimed. At these locations, the following stratigraphic division can generally be made, with the uppermost stratum listed first:
- Reclamation fill

- Holocene marine deposit

- Pleistocene alluvium

- Weathered rock

Depending upon the location, these strata may be present in various thicknesses or may be completely absent.

\subsection{Reclamation fill}

The composition of reclamation fill can vary significantly depending upon the fill type, source and placement method. The General Specification for Civil Engineering Works (Civil Engineering and Development Department, 2018) details different fill types. An end-tipped ungraded rock fill can possess a permeability in excess of $1 \mathrm{~m} \mathrm{~s}^{-1}$, as suggested by back-analyses of groundwater extraction, tidal lag and slurry loss in excavations. However, fill comprising predominantly sand would typically have a permeability in the range $10^{-4} \mathrm{~m} \mathrm{~s}^{-1}$ to $10^{-3} \mathrm{~m} \mathrm{~s}^{-1}$. Particularly in public fill, whose grading can vary over a wide range, inclusions of silt and clay might be present. Mud waves generated during fill deposition might also result in zones of disturbed marine clay distributed towards the base of the fill.

The fill generally behaves as an unconfined aquifer. An aquifer is a stratum with a permeability sufficiently high as to transmit and yield significant volumes of water. The aquifer is unconfined in that it is not confined by an overlying impermeable stratum, resulting in the groundwater table being at atmospheric pressure. Where the fill is sufficiently connected to the sea, the groundwater level in the fill will fluctuate tidally. Rainfall, surface runoff and adjacent groundwater extraction also affect the groundwater level.

\subsection{Marine deposit}

The marine deposit typically occurs as a clay with 
a permeability of around $10^{-9} \mathrm{~m} \mathrm{~s}^{-1}$ to $10^{-8} \mathrm{~m} \mathrm{~s}^{-1}$. The clay acts as an aquiclude. An aquiclude is a stratum with a permeability sufficiently low that flow through and from it is generally negligible.

\subsection{Alluvium}

The alluvium is highly variable, and generally comprises interbedded sands, silts and clays varying from a few centimetres to several tens of metres in thickness. In offshore settings, the alluvium in Hong Kong normally behaves as a confined aquifer because it underlies the marine deposit, which acts as an aquiclude, meaning that the hydraulic head in the alluvium can rise above the upper surface of the alluvium.

Near the coast, the alluvium is recharged from elevated groundwater retained in surrounding hills, causing the groundwater level in the alluvium to rise higher than mean sea level by a few metres. In some cases, an artesian head is observed, where the groundwater level rises above the ground surface. When the alluvium is dewatered, clay layers in the alluvium can act as aquicludes and retain perched water. A similar phenomenon can occur in the fill above clay layers.

\subsection{Weathered rock}

The composition of the weathered rock varies greatly depending upon the parent rock type, the degree of weathering and geological features such as discontinuities in the rock mass. Saprolite corresponds to weathered rock which retains the structure, texture and fabric of the parent rock, and typically comprises decomposition Grade $\mathrm{V}$ and in instances Grade IV (Geotechnical Engineering Office, 2007). Grade VI is termed residual soil and has lost its original rock features. In general, granitic saprolite is encountered as a sandy silt, sometimes with some clay or gravel, and in the author's experience has a permeability typically ranging from $10^{-8} \mathrm{~m} \mathrm{~s}^{-1}$ to $10^{-6} \mathrm{~m} \mathrm{~s}^{-1}$. However, faults are generally more transmissive, and the permeability can be highly heterogeneous. The more permeable regions act as an extension to the alluvial aquifer, whilst the deeper, less weathered regions generally define the lower boundary of the alluvial aquifer.

\section{Practice in groundwater monitoring}

\subsection{Fully-grouted piezometers}

In Hong Kong, groundwater level monitoring instruments generally take two forms: either (i) a perforated standpipe, or (ii) an installation comprising a blank standpipe with a piezometer tip installed within a confined sand response zone. Geoguide 2 (Geotechnical Engineering Office, 2017) refers to the two instruments as a standpipe and an open-hydraulic piezometer respectively. The open- hydraulic piezometer is intended to measure the porewater pressure at the elevation of the piezometer tip. An illustration of the two instruments extracted from Geoguide 2 is presented in Figure 1. The instrument detail specified in Geoguide 2 has remained unchanged since the first edition published in 1987.

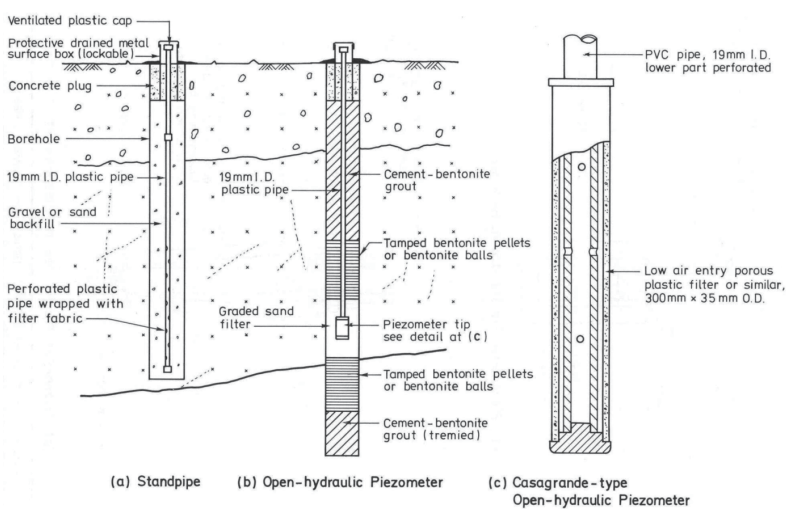

Figure 1. Typical illustrations for groundwater level monitoring instruments in Hong Kong as presented in Geoguide 2.

Over the past decade, vibrating wire piezometers have been increasingly adopted in Hong Kong, in part due to the benefit of automatic datalogging. Vibrating wire piezometers rely upon the displacement of a sensor diaphragm to measure porewater pressure, requiring only an extremely small volume of water to register a pressure change. In contrast, the open-hydraulic piezometer specified in Geoguide 2 relies upon the passage of a significant volume of water through the sand response zone to enable the water level in the standpipe to equilibrate with the head in the soil immediately surrounding the response zone. The blank standpipe and the sand response zone required for the open-hydraulic piezometer are unnecessary when using a vibrating wire piezometer (Mikkelsen \& Green, 2003). Nonetheless, Hong Kong practitioners have retained the standpipe and response zone, by simply lowering the vibrating wire piezometer down the standpipe.

Since the 1960s, the global industry began to recognise the benefits of doing away with the sand response zone and standpipe, and simply sealing a vibrating wire piezometer directly within grout (Vaughan, 1969), giving rise to the fully-grouted piezometer. The fully-grouted piezometer demonstrated a performance superior to other methods of pore pressure measurement, as demonstrated recently on the Crossrail Project in the United Kingdom (Wan \& Standing, 2015).

Eliminating the standpipe and sand response zone when employing a vibrating wire piezometer has the following benefits (Mikkelsen \& Green, 2003):

- Immediate response to pore pressure changes: The response time of the open-hydraulic piezometer is limited by the significant volume 
of water flow required to effect a change in level in the standpipe. This becomes particularly apparent with rapid pressure changes, as might accompany abrupt changes in pumping or from tidal fluctuation, or if the response zone is located within a low-permeability stratum. In a fullygrouted installation, the grout transmits pressure changes practically instantaneously, and the response is immediate.

- Narrower elevation range for pore pressure measurement: If the sand response zone intercepts soil whose total head varies with depth, the piezometer reading would be affected by the higher-permeability soil. The fullygrouted piezometer registers the pore pressure immediately outside the grout annulus and is more effective at returning the pore pressure at a particular elevation.

- Rapid installation: Bentonite pellets are typically placed above and below a sand response zone to prevent the migration of sealing grout into the sand. Hydration of the pellets typically takes one or two days, lengthening installation time considerably compared with that for fully-grouted piezometers.

- Potential for multiple piezometer installation in a single borehole: For open-hydraulic piezometers, the specification of standpipes complicates the sealing of response zones, limiting the number of piezometers that can be installed within the same hole. With only cables rising to the surface, fully-grouted installations facilitate the placement of multiple piezometers within a single hole. Fully grouting the installation also reduces the risk of leakage between piezometers within the same hole.

At the Hong Kong Boundary Crossing Facilities reclamation, the response of fully-grouted piezometers and piezometers embedded within sand response zones and installed with a standpipe was compared. Six pairs were installed within the alluvial sand and sand fill which showed a tidal influence. Each pair comprised one fully-grouted piezometer and one installed within a sand response zone, separated by only a few metres in plan and elevation. The fully-grouted piezometers registered the tidal fluctuation with a shorter lag and a higher amplitude, as demonstrated in Figure 2 for a pair of piezometers installed in the fill. The fully-grouted piezometers also reacted significantly faster to porewater pressures induced by pumping, yielding data more suitable for pumping test analysis.

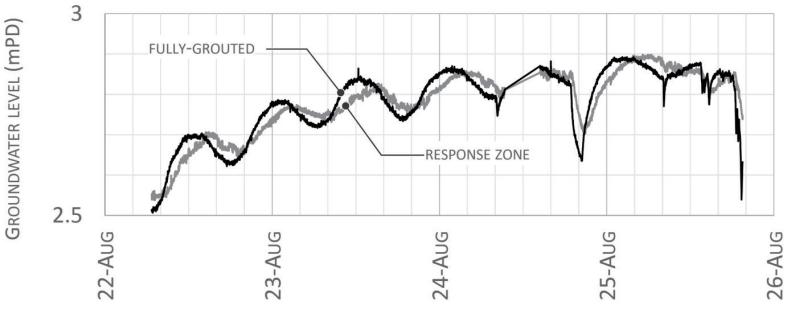

Figure 2. Comparison of the response of a fully-grouted piezometer with one installed in a sand response zone.

\subsection{Measurement location}

A cofferdam wall is intended to maintain a difference in groundwater level across the wall. In the case where the wall is considered impermeable relative to the surrounding soil or rock, groundwater can be assumed to flow into the cofferdam below the toe of the wall. Application of Darcy's law, conservation of volume and satisfaction of the boundary conditions results in a flow net around the wall.

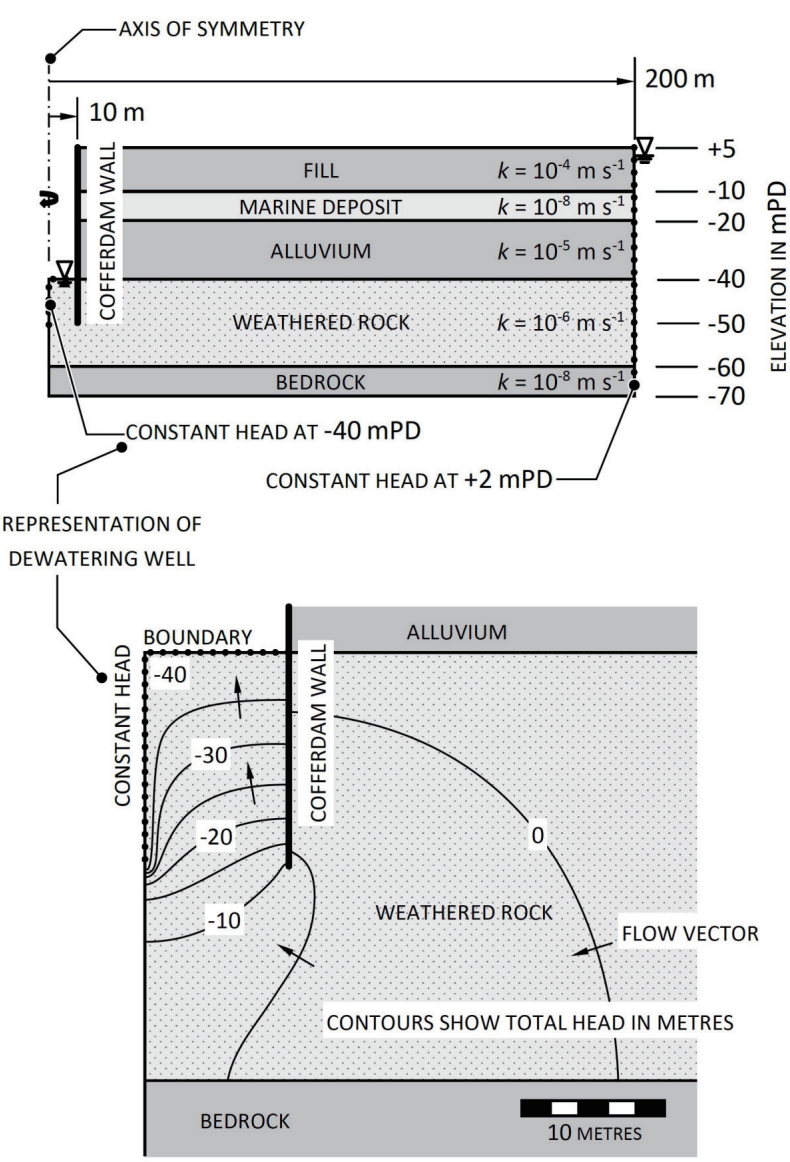

Figure 3. Example of a flow net arising from dewatering within a circular shaft in typical Hong Kong stratigraphy.

Figure 3 illustrates contours of total head from a flow net generated by dewatering inside an impermeable circular shaft installed in typical Hong Kong stratigraphy. In this 
case, the change in total head across the wall almost entirely occurs within the weathered rock owing to the overlying alluvium possessing a permeability an order of magnitude greater. The total head varies with both depth and lateral extent around the cofferdam wall. This has the following implications:

- In Hong Kong, a one-metre drawdown limit is commonly imposed outside the cofferdam, although this can vary depending upon the allowable movement of the adjacent structures. In the case of Figure 3, a drawdown of around $10 \mathrm{~m}$ is expected near the wall toe, and the onemetre limit would be exceeded for a considerable distance within the weathered rock. The impact of dewatering should instead be assessed by comparing field pore pressure measurements with flow net predictions, allowing for depth and proximity to the wall.

- It is common practice to employ a standpipe inside the cofferdam to monitor the progress of drawdown. Figure 3 shows that terminating the standpipe too deep can lead to groundwater level measurements substantially higher than what would be encountered during excavation. For the case in Figure 3, a standpipe extending to the cofferdam toe level would register a drawdown 20 $\mathrm{m}$ less than the imposed drawdown. The progress of groundwater level drawdown should instead be judged using a piezometer installed at a depth within three metres below the final excavation level.

\subsection{Perched water}

Persistent clay layers are likely to retain perched water if the surrounding aquifer is dewatered. On construction projects that the author has been involved with, perched water has been encountered above the marine clay, alluvial clay beds and clay distributed within the fill. Any perched water would tend to flow into a perforated standpipe and would influence the measured groundwater level depending upon the measurement method, as illustrated in Figure 4:

- A dipmeter lowered within the standpipe would register the level of the perched water table, being sensitive to the first encounter of dampness.

- A vibrating wire piezometer located at the base of the standpipe would be less affected, with the degree of influence depending upon the permeability of the surrounding ground.

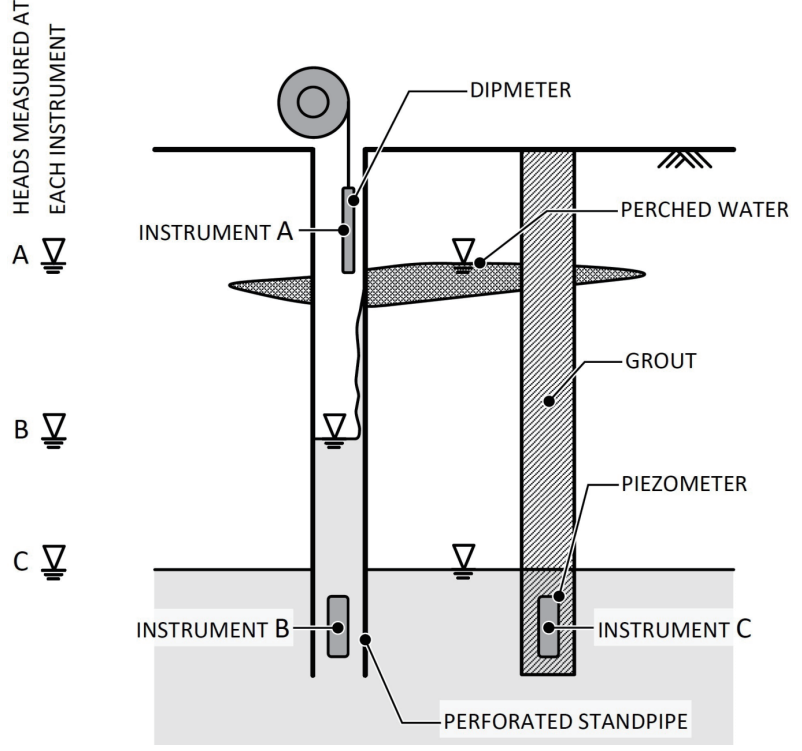

Figure 4. Effects of perched water on groundwater level readings from a dipped perforated standpipe and a fullygrouted piezometer.

In Hong Kong, perforated standpipes are commonly used to monitor drawdown, and the true dewatered groundwater level in the aquifer is frequently masked by the ingress of perched groundwater. Figure 4 shows that a fully-grouted piezometer, or at least one installed within a confined response zone, would not be affected by any overlying perched water.

\subsection{Tidal fluctuation}

Groundwater levels in fill sufficiently close to the sea will be susceptible to tidal fluctuation, with an attenuation and lag that depends upon the fill permeability and storage. At the West Kowloon Terminus of the Express Rail Link, the fill was predominantly sand and the tidal fluctuation became unnoticeable approximately $100 \mathrm{~m}$ from the seawall. In contrast, in the ungraded rock fill at another coastal site in Hong Kong, the tide was practically unattenuated $300 \mathrm{~m}$ from the seawall.

Near the sea, the tide also influences groundwater levels in alluvium underlying marine deposits. At the Hong Kong Boundary Crossing Facilities reclamation, a tidal response amplitude of $0.2 \mathrm{~m}$ was measured in the alluvial sand due to the fluctuating weight of water acting upon the marine clay at the seabed.

Tidal fluctuation measured in the fill indicates an abundant recharge flow, in which case the groundwater level drawdown outside a cofferdam might be unnoticeable, even in the case of significant leakage. The high hydraulic gradients generated by the leakage can still cause the migration of fines with subsequent void formation and collapse. In this case, the typically applied criterion of one metre on the groundwater level drawdown outside a 
cofferdam might never be exceeded and the criterion would fail to serve as an adequate indicator of the impact of a leakage. Instead, the measured and predicted extraction rates and groundwater levels at locations within the cofferdam should be compared to establish the existence, location and magnitude of leakages.

Either the lag or the attenuation of the tidal response can be harnessed to yield a very rough estimate of the fill permeability (Fetter, 2001). Using the attenuation:

$$
k=\frac{\pi C_{s}}{t_{0} d}\left(\frac{L}{\ln \left(\frac{h^{\prime}}{h}\right)}\right)^{2},
$$

and using the lag:

$$
k=\frac{t_{0} C_{s}}{4 \pi d}\left(\frac{L}{t_{1}}\right)^{2},
$$

where:

$C_{s} \quad$ is the specific yield of the fill

$d$ is the thickness of the fill aquifer

$h$ is the peak-to-peak tidal amplitude in the sea

$h^{\prime} \quad$ is the peak-to-peak tidal amplitude at the measurement point in the fill

$L \quad$ is the distance of the measurement point to an equivalent vertical recharge boundary with the sea

$t_{0} \quad$ is the tidal period

$t_{1} \quad$ is the lag between the peak tide at the measurement point and that in the sea

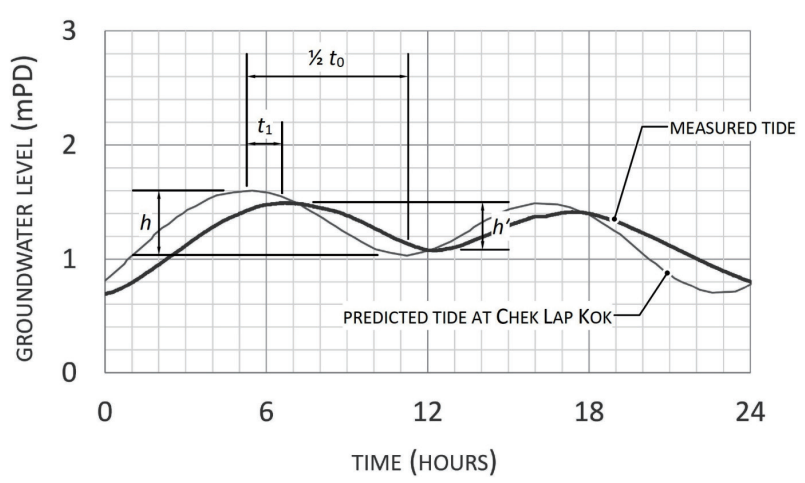

Figure 5. Tidal response measured at Black Point Power Station compared with the predicted tide. The parameters shown refer to Equation 1 and Equation 2.

Figure 5 presents the tidal fluctuation recorded in the rock fill at Black Point Power Station. Assuming the parameters annotated in the figure, with $C_{s}=0.3, d=15 \mathrm{~m}$ and $L=100 \mathrm{~m}$, gives permeabilities in the range of $0.03 \mathrm{~m} \mathrm{~s}^{-1}$ to $0.2 \mathrm{~m} \mathrm{~s}^{-1}$.

For pumping tests in Hong Kong, it is common practice to establish baseline groundwater levels over a 24-hour period immediately prior to pumping. During this period, a unique baseline groundwater level is determined for each groundwater monitoring instrument by gathering data at a minimum interval of four hours. Where groundwater levels are tidal, this monitoring frequency is inadequate for establishing the tidal characteristics, and levels should be automatically logged at a minimum interval of 10 minutes. The determination of a constant baseline groundwater level for each instrument is also inappropriate when the instrument is influenced by tide or other factors unrelated to extraction. Instead, groundwater levels measured during the test should be compared with far-field reference measurements or the tide recorded at the closest tidal station.

Piezometer readings should be corrected for atmospheric pressure changes by reserving one piezometer inside the site office to log air pressure at the same sampling frequency. Left uncorrected, a 30 millibar change in air pressure would introduce an error of $0.3 \mathrm{~m}$.

Like the baseline period, groundwater levels throughout the test should be automatically logged at a minimum interval of 10 minutes in general. At the beginning of the test however, when changes take place rapidly, measurements should be taken more frequently, especially since time is typically plotted on a logarithmic axis when deducing hydrogeological parameters from pump test data. Many loggers on the market allow adjustment of the monitoring frequency during the test. Intermittent manual dipping can be performed if the downloading and processing time for autologged readings frustrates urgent decision-making.

Once groundwater levels have reached the target drawdown level within the cofferdam, it is common in Hong Kong to stipulate that groundwater levels measured at all instruments be held at a steady state for a minimum of 72 hours. A steady state is defined as rates of change in groundwater level not exceeding $0.1 \mathrm{~m} \mathrm{hr}^{-1}$. Under the influence of tide, the definition of a steady state should consider the bi-diurnal tidal cycle, and allowance should also be made for storm surge, rainfall, and tidal springs and neaps.

\section{Practice in groundwater extraction and recharge}

\subsection{Filter pack and well screen}

Figure 6 illustrates a typical dewatering well installation in Hong Kong. The well screen is separated from the surrounding soil by an annulus of coarser material called a filter pack, which stabilises the ground and limits the ingress of soil into the well. In Hong Kong, the specification of the well screen and filter pack appears to be limited by materials availability and sub-contractor experience. 


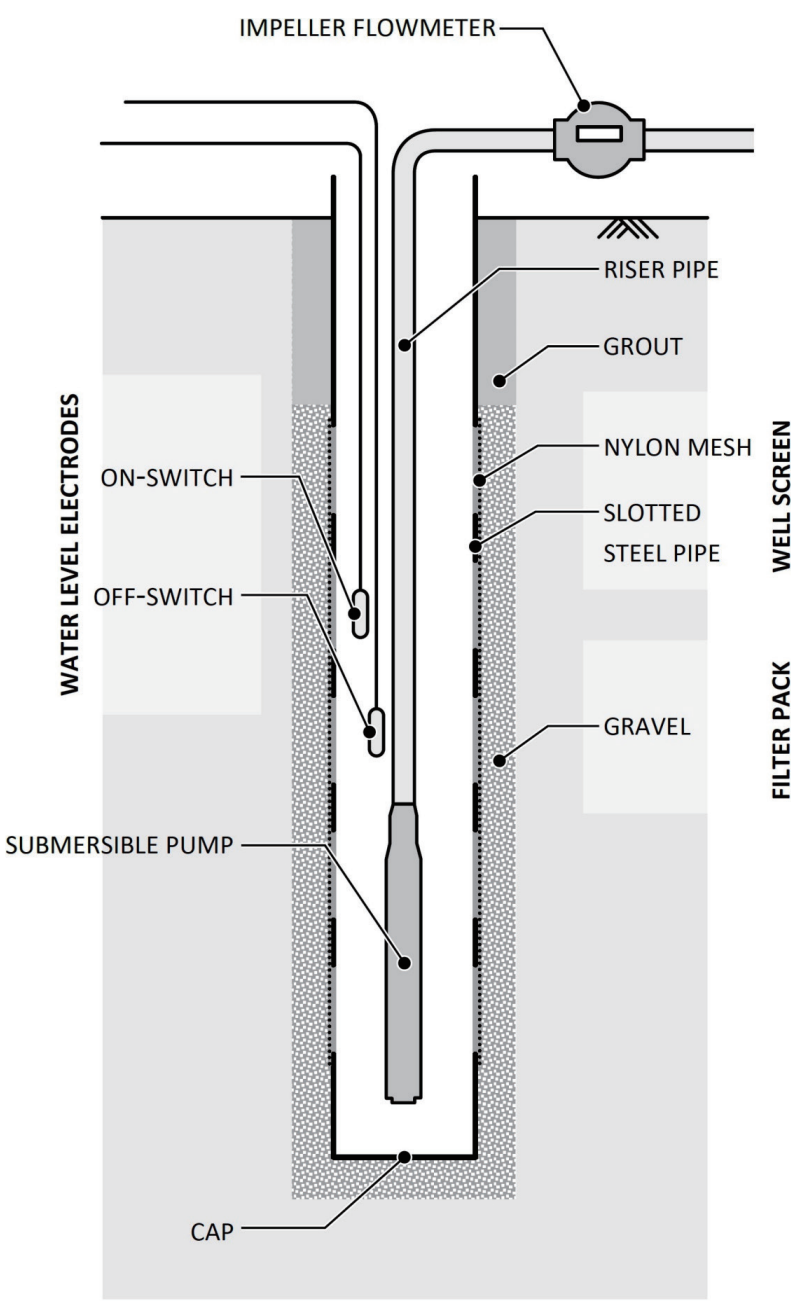

Figure 6. Typical dewatering well installation in Hong Kong.

The well screen typically consists of a mild steel pipe which features flame-cut vertical slots and is wrapped with nylon mesh. Designs typically specify an open-area ratio of $10 \%$ for the slotted pipe; the open-area ratio equals the area of the slots divided by the total surface area of the screen. To minimise head losses across the screen, it is generally advisable to use an open area as large as possible subject to filtering constraints and no less than 5\% of the total surface area (Somerville, 2005; Cashman and Preene, 2013).

The nylon mesh wrapping the pipe itself has an openarea ratio of approximately $50 \%$. Wrapped once around the pipe, the net open area of the well screen reduces to $5 \%$. It is typical however to wrap the mesh multiple times around the pipe, resulting in an open area significantly less than $5 \%$ and a consequent high head loss across the screen. Well installation should be supervised to ensure that only a single layer of mesh is wrapped around the slotted pipe. The mesh should be tightly and securely wrapped since it is easy to damage the mesh when lowering the screen into the hole, particularly through an aquifer possessing an artesian head.

Machine-slotted screens need no nylon mesh and are preferred to screens slotted by hand. Machine-slotted screens are routinely used overseas, with typical slot sizes ranging from 0.5 to $1.0 \mathrm{~mm}$.

The grading of the filter pack should be selected to stabilise the aquifer and to prevent the migration of the filter pack itself and fines from the aquifer through the screen. In Hong Kong, a uniform aggregate size anywhere between 3 and $10 \mathrm{~mm}$ is typically specified for the filter pack, yet there appears to be little justification for choice of size in designs.

Appendix 7 of CIRIA Report R113 (Somerville, 2005) provides filter pack design guidance. Figure 7 presents a filter pack for alluvial sand designed according to CIRIA R113, whilst Figure 8 presents one for sand fill. The curves representing the ranges of grading for the aquifers are derived from samples taken at the Hong Kong Boundary Crossing Facilities reclamation. A $2 \mathrm{~mm}$ mesh size was assumed for the screen, defined as parameter $D$ on the figures. The figures demonstrate that a $3 \mathrm{~mm}$ uniform gravel would be suitable for both the alluvial sand and the sand fill.

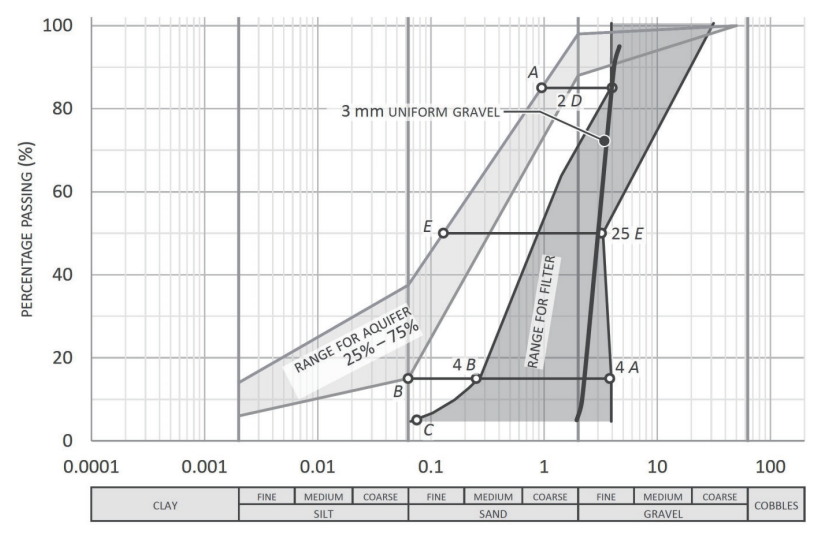

PARTICLE SIZE $(\mathrm{mm})$

Figure 7. Filter pack specification for alluvial sand following CIRIA R113.

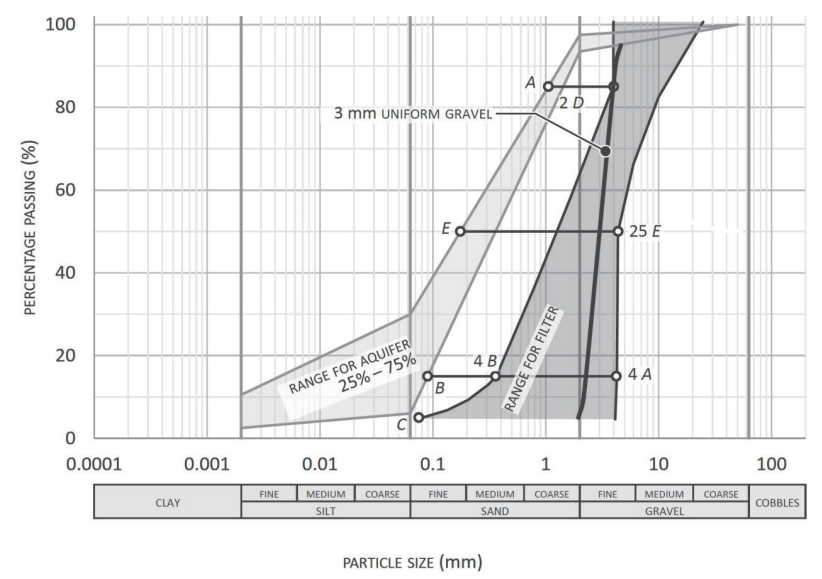

Figure 8. Filter pack specification for sand fill following CIRIA R113. 
For finer-grained aquifers such as alluvial silt, a graded filter pack with a finer mesh would be necessary to prevent the migration of silt-sized particles. In this case, the filter pack would comprise a sand-gravel mixture, which would require placement by tremie pipe to prevent segregation. Compaction of the filter pack should be allowed for by extending the filter pack up to one metre above the slotted screen. For coarser-grained aquifers such as rock fill, a filter pack could even be done away with, requiring only a coarse gravel to backfill the annulus between the screen and the temporary casing during extraction. The filter pack aggregate should be specified as well-rounded to minimise resistance to flow. Centralisers should be fitted around the screen at six-metre intervals to ensure both an even thickness of filter pack around the screen (Powers et al., 2007) and a straight screen.

For wells penetrating multiple aquifers, the specification of the filter pack and well screen should differ with depth according to the particle size distribution of each aquifer. Where the well intercepts an aquiclude, a blank casing with a grouted annulus should be adopted to maintain separation of the aquifers above and below.

\subsection{Well development}

The yield of a dewatering well will be substantially improved through well development. Well development involves removing drilling residue and expelling fines from the aquifer within a zone immediately surrounding the well, so increasing the effective diameter and reducing resistance to inflow.

Well development is practically essential for water abstraction to maximise efficiency. For construction dewatering, efficiency is usually secondary, but may be important where cumulative inflow is substantial, for instance when dewatering without a cut-off, or for longterm dewatering during the operational phase. When dewatering an unconfined aquifer, minimising well loss by well development may be particularly important to drawdown the groundwater table as close as possible to the base of the aquifer.

Development involves inducing an intermittent flow into the well, or preferably reversal of flow to disturb any fines lodged in gaps between coarser particles by the inflow phase. Many of the well development techniques commonly adopted worldwide would require the introduction of new tools and methods to the Hong Kong industry, such as jetting or surge blocks (Powers et al., 2007; Ahmed et al., 2014). Developing wells by airlifting is also common.

Nonetheless, the well may be partially developed without any additional equipment by cyclic pumping. To maximise the inflow volume, the off-switch water level electrode should be located just above the top of the pump, whilst the on-switch electrode should be positioned a few metres below the ambient groundwater level. Rapid evacuation of the well can be achieved by installing a pump of sufficient power or by injecting compressed air. The development should continue until the discharge becomes clear with a low sand content, as measured by sampling water at the outlet.

The effectiveness of cyclic pumping is limited by the inability to reverse the flow into the well. Flow reversal can be induced by injecting compressed air into the bottom of the well through a pipe. The air can be used to lift a column of water to the top of the well and drop it rapidly to induce flow into the aquifer.

\subsection{Pump specification}

The deep dewatering wells in Hong Kong are typically fitted with turbine submersible pumps. The flow rate from a pump varies with the head difference applied between the inlet and outlet of the pump according to a performance curve unique to each type of pump. The head difference is termed the total dynamic head and comprises the sum of:

- frictional head losses in the pipework, valves, fittings and pump;

- the velocity head loss at the outlet to atmosphere; and

- the elevation head between the inlet and the outlet to atmosphere.
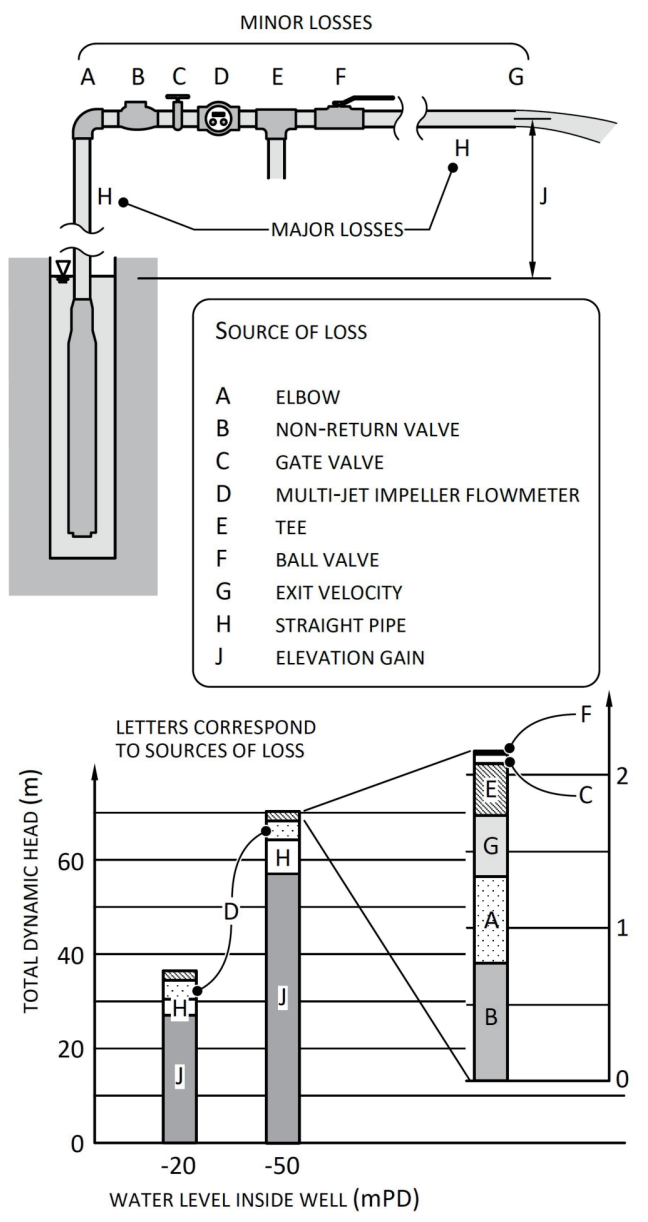

Figure 9. Typical dynamic head losses for dewatering wells installed to two different depths. 
Figure 9 estimates the relative contributions to total dynamic head for two dewatering wells installed to different depths: one to dewater the fill to $-10 \mathrm{mPD}$ and the other to depressurise the alluvium to $-40 \mathrm{mPD}$. The estimates assume a well head configuration typically used in Hong Kong and the following assumptions:

- water levels inside the two wells at $-20 \mathrm{mPD}$ and $-50 \mathrm{mPD}$ to allow for $10 \mathrm{~m}$ head losses across the screen and in the surrounding soil

- a two-inch pipe diameter as typically adopted in Hong Kong

- the pump suspended with its intake immediately below the water surface inside the well

- discharge to a tank at $+7 \mathrm{mPD}$

- a $20 \mathrm{~m}$ pipe length above ground

- a flow rate of $20 \mathrm{~m}^{3} \mathrm{hr}^{-1}$; an array of wells spaced at $15 \mathrm{~m}$ would lower the groundwater level at $1 \mathrm{~m}$ $\mathrm{hr}^{-1}$

In addition to the elevation head, frictional losses contribute between $10 \mathrm{~m}$ and $15 \mathrm{~m}$ to the total dynamic head, and it is recommended that in the absence of a detailed head loss calculation that a $20 \mathrm{~m}$ head be added to the elevation head to obtain the total dynamic head required of the pump.

Assuming a pump efficiency of $50 \%$, the wells installed in the fill and alluvium would require pumps with a minimum power of $4 \mathrm{~kW}$ and $8 \mathrm{~kW}$ respectively. Typical performance curves for $4 \mathrm{~kW}$ and $8 \mathrm{~kW}$ submersible pumps are plotted in Figure 10. The flow rate would be a maximum at the start of pumping and gradually reduce as groundwater levels reach a steady state, causing the operating points highlighted on Figure 10 to shift leftward. Installing pumps with half the power might still be adequate under steady state conditions but the time required to drawdown the groundwater levels may be unacceptable and would leave little contingency in case of pump failure or inundation events.

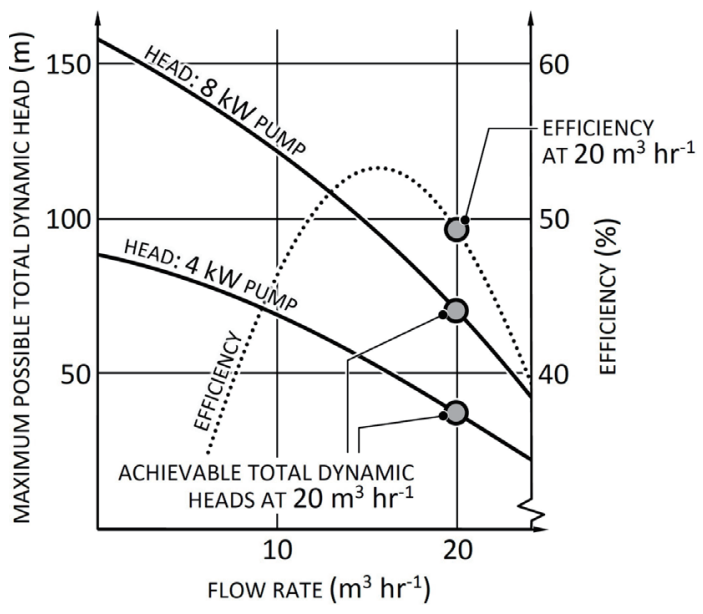

Figure 10. Typical performance curves for $4 \mathrm{~kW}$ and 8 $\mathrm{kW}$ submersible pumps with operating points shown corresponding to the wells considered in Figure 9.

\subsection{Recharge wells}

Recharge wells in Hong Kong are typically detailed like the perforated standpipe shown in Figure 1. However, in essentially performing the opposite function of a dewatering well, a recharge well should be designed based upon a dewatering well but without a pump, with a screen diameter significantly wider than a standpipe. An example of a recharge well detail is illustrated in Figure 11. Wells recharging a confined aquifer are likely to operate more efficiently than those recharging an unconfined one.

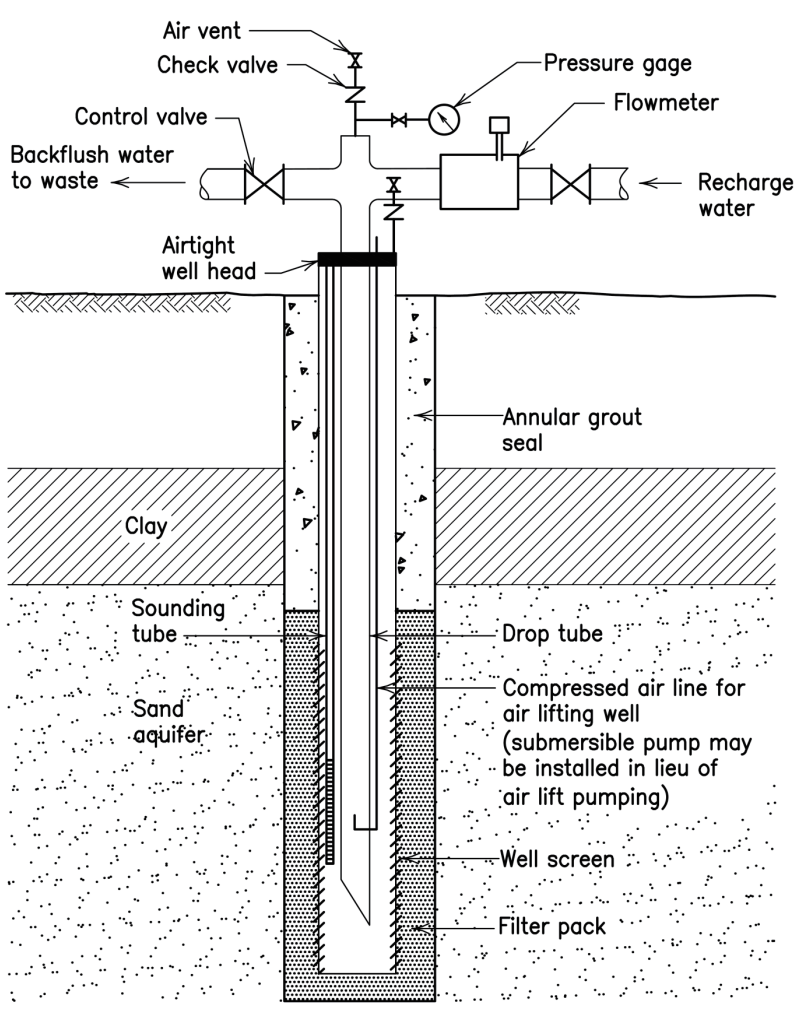

Figure 11. Details of a typical recharge well.

The larger diameter also reduces the potential for clogging of the recharge well. Recharge wells are far more susceptible to clogging than dewatering wells due to the direction of flow. A dewatering well will tend to remove fine material from the immediately surrounding aquifer, developing a localised zone of higher permeability and improving efficiency. With a recharge well any fines present in the recharge water will tend to accumulate in the soil around the screen with a consequent reduction in efficiency with time. Pressurisation of the well affects clogging, and this should be considered when designing the annulus.

Well development is even more paramount for a recharge well than for a dewatering well since the recharge well cannot develop progressively during operation. The development methods for dewatering wells described earlier equally apply to recharge wells. Recharge wells would likely require regular backflushing during operation, 
which can be facilitated by incorporating a compressed air pipe in the design.

The quality of recharge water must be a similar quality to the receiving water in the aquifer to ensure minimal maintenance. Precipitates arising from potential chemical reactions between the recharge water and groundwater can be reduced by recycling the discharge from dewatering. Entrained air and suspended solids should be removed by allowing an adequate duration in a sedimentation tank. Sand and granular activated carbon filters can remove smaller colloidal particles. The addition of chlorine at a concentration of up to $10 \mathrm{ppm}$ will eradicate microorganisms generating troublesome precipitates and slimes.

\section{Conclusion}

The current practice for construction dewatering in Hong Kong is strongly influenced by local practice. This paper reviews the current practice and recommends best practice borne out of groundwater engineering principles. By considering the locally available knowledge and technology, the recommended guidance should be straightforward to implement by client, designer and contractor alike, and when heeded should result in cost and programme savings.

\section{Notes on contributor}

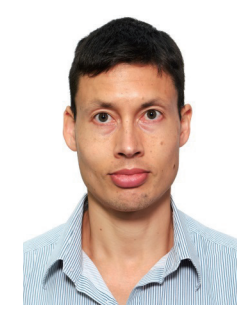

Dr Rich Laver currently works as a senior geotechnical engineer at Golder Associates.

Rich moved to Hong Kong ten years ago after graduating from the University of Cambridge for both his doctorate and starred-first undergraduate degree. Rich has spent almost all his time in Hong Kong working for the specialist geotechnical consultancy Geotechnical Consulting Group (Asia), now Golder Associates. Rich attained chartership in 2015.

In his role, Rich has provided expert geotechnical services in areas including dewatering and pumping tests, groundwater modelling, reclamations, instrumentation and monitoring, distributed fibre optic strain sensing, grouting, excavation and lateral support, and reinforced earth retaining walls. Major projects which Rich has worked on include the Central-Wanchai Bypass, the West Kowloon Terminus, the Tuen Mun-Chek Lap Kok Link Southern Landfall, Abu Dhabi Plaza in Kazakhstan, and the Hong Kong International Airport Third Runway System, where Rich is currently working on site.

In his free time, Rich enjoys running, studying nutrition, cooking, learning Cantonese, spending time with his family, and getting involved at church.

\section{References}

[1] Ahmed N, Taylor SW and Sheng Z (2014). Hydraulics of wells - design, construction, testing and maintenance of water well systems. s.l.: American Society of Civil Engineers.

[2] Cashman PM and Preene M (2013). Groundwater lowering in construction - a practical guide to dewatering. $2^{\text {nd }}$ ed. London: Taylor \& Francis.

[3] Civil Engineering and Development Department (2018). Section 21 - Marine Works. In: General Specification for Civil Engineering Works. 2006 Edition. Hong Kong: The Government of the Hong Kong Special Administrative Region.

[4] Fetter CW (2001). Applied Hydrology. $4^{\text {th }}$ ed. Upper Saddle River (New Jersey): Prentice-Hall.

[5] Geotechnical Engineering Office (2007). Engineering Geological Practice in Hong Kong. GEO Publication No. 1/2007. Hong Kong: The Government of the Hong Kong Special Administrative Region.

[6] Geotechnical Engineering Office (2017). Geoguide 2 - Guide to site investigation. Hong Kong: The Government of the Hong Kong Special Administrative Region.

[7] Mikkelsen PE and Green EG (2003). Piezometers in fully grouted boreholes. Oslo, Norway, s.n.

[8] Powers PJ, Corwin AB, Schmall PC and Kaeck WE (2007). Construction dewatering and groundwater control - new methods and applications. $3^{\text {rd }} \mathrm{ed}$. s.1.:John Wiley and Sons.

[9] Somerville SH (2005). CIRIA R113: Control of groundwater for temporary works. London: Construction Industry Research.

[10] Vaughan PR (1969). A note on sealing piezometers in boreholes. Géotechnique, 19(3), pp. 405-413.

[11] Wan MSP and Standing JR (2015). Field measurement by fully grouted vibrating wire piezometers. In: Crossrail Project: Infrastructure design and construction. London: ICE Publishing, pp. 519-538. 